\title{
Blast Resistance of Slurry Infiltrated Fibre Concrete with Waste Steel Fibres from Tires
}

\author{
Martina Drdlová ${ }^{1}$, Oldřich Sviták ${ }^{1}$, Petr Bibora ${ }^{1}$, Miloslav Popovič ${ }^{2}$, René Čechmánek ${ }^{1}$ \\ ${ }^{1}$ Research Institute for Building materials, Applied Research and development, Brno, Czech Republic \\ ${ }^{2}$ SVS FEM s.r.o., Brno, Czech Republic
}

\begin{abstract}
The utilization of waste steel fibres (coming from the recycling process of the old tires) in production of blast resistant cement based panels was assessed. Waste fibres were incorporated in slurry infiltrated fibre concrete (SIFCON), which is a special type of ultra-highperformance fibre reinforced concrete with high fibre content. The technological feasibility (i.e. suitability of the waste fibres for SIFCON technology) was assessed using homogeneity test. Test specimens were prepared with three volume fractions $(5 ; 7.5$ and $10 \%$ by vol.) of waste unclassified fibres. SIFCON with industrial steel fibres (10\% by vol.) and ultra-highperformance fibre concrete with industrial fibres were also cast and tested for comparison purposes. Quasi-static mechanical properties were determined. Real blast tests were performed on the slab specimens (500x500x40 mm) according to the modified methodology M-T0-VTU0 10/09. Damage of the slab, the change of the ultrasound wave velocity propagation in the slab specimen before and after the blast load in certain measurement points, the weight of fragments and their damage potential were evaluated and compared. Realized tests confirmed the possibility of using the waste fibres for SIFCON technology. The obtained results indicate, that the usage of waste fibres does not significantly reduce the values of SIFCON flexural and compressive strength at quasi-static load - the values were comparable to the specimens with industrially produced fibres. With increasing fibre content, the mechanical parameters are increasing as well. Using of the waste fibres reduces fragmentation of SIFCON at blast load due to the fibre size parameters. Using of low diameter fibres means more fibres in the matrix and thus better homogeneity of the whole composite with less unreinforced areas. Regarding the blast tests, the specimen with waste steel fibres showed the best resistance and outperformed also the specimen with commercial fibres. Using of waste fibres in SIFCON technology can reduce the price of this composite by $70 \%$ by keeping the original SIFCON extraordinary properties, which makes it very competitive material in the concrete area.
\end{abstract}

\section{Introduction}

It is estimated that over 4 billion used tires are generated every year [1]. A typical tire consists of approximately $47 \%$ rubber, $22 \%$ carbon black, $17 \%$ steel cords, $5 \%$ fabrics, and the remaining percentage consists of some other minor additives [2]. Every passenger car tire thus contains about $1.3 \mathrm{~kg}$ of steel fibres, which can be reused. Nowadays, the steel obtained from the recycling process is mostly used as a feedstock in the production of new steel. Using tire waste fibres in concrete technology is limited due to the nature of the obtained fibres - in particular the high diversity of fibre geometry, contamination and bulk nature of the product. Further processing (cutting, selecting and cleaning) of the fibres enables to prepare more suitable material for the concrete reinforcement and brings satisfactory results, but is expensive and demanding. On the other hand, the tire fibres are made from high strength carbon steel with a tensile strength as high as 2,200-2,750 MPa [3], so they seem to be promising reinforcing material. Several studies were performed focused on mechanical properties of concrete with classified fibres $[1,4,5,6]$ The pull-out behavior of the recovered fibers may be similar to those of the commercial fibers which may be attributed to the irregular undulations of the fibers as a result of the shredding process that can increase mechanical bonding [6] and [7]. Mechanical properties of 
concrete containing waste steel fibers may be improved due to the crack-bridging effect of the fibers in concrete similar to the concretes produced with commercial fibers [8], [5] and [9].

Finding the way how to reuse this type of fibers as the concrete reinforcement can save the costs connected with fibreconcrete manufacturing. As the traditional concrete technology is difficult to be adopted when using not classified waste fibres (the fibres tend to stay in bulks and the proper disintegration and homogenous dispersion is difficult to achieve in higher fiber dosage), the slurry infiltration technology was tested in this study. Slurry infiltrated fibre concrete - SIFCON was first developed in 1979 in USA, by incorporating large amounts of steel fibres in cement-based composites [10]. SIFCON is prepared by infiltrating pre-placed fibres with fine grain aggregate mortar. The fibre volume fraction of traditional fibre reinforced concrete is limited, because excessive amount of the fibres affects the workability of the fresh concrete in a negative way. This limits the fibre volume $\mathrm{V}_{\mathrm{f}}$ to $1-$ $5 \%$, depending on the type of fibre used and the required workability of the mixture. SIFCON specimens can be produced with $\mathrm{V}_{\mathrm{f}}$ between $5 \%$ and $30 \%$ [10], the fibre volume depends on the fibre geometry, length and diameter and vibration of the fibres during their placement process. SIFCON possesses excellent mechanical propertiesextraordinary behaviour in flexure and punching shear coupled with very good energy-absorption characteristics [11, 12]. Due to extraordinary ductility of SIFCON, caused by high fibre content, it seems to be very promising material mostly for applications in structures subjected to impact load. The high fibre content is connected with high production costs, so the replacement of the industrial fibres by waste fibres would significantly decrease the price of the whole composite.

The main objective of the work presented herein is to provide more information about the effects of steel fibers recovered from tires on the mechanical parameters of SIFCON, with focus on its behaviour under blast loading. According to the authors knowledge, there is no study dealing with this topic currently available. The modified methodology for blast resistance assessment is also presented.

\section{Experimental}

\subsection{Preparation of specimens and test methods}

Waste steel fibers recovered from scrap tires were obtained from recycling plant "RPG recycling". Fibers were partly contaminated by rubber and textiles (see Figure 1), and had variations in their geometrical properties.

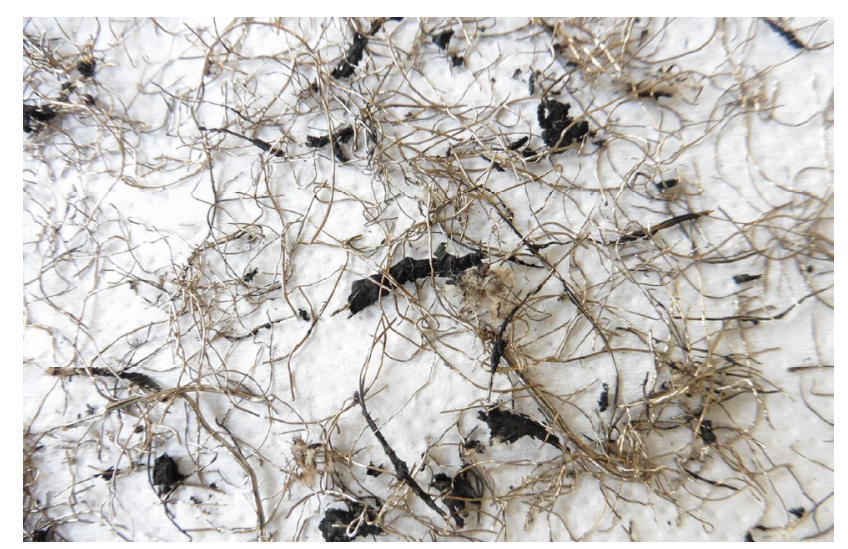

Fig. 1. Waste fibres from recycling process of the tires

The geometrical characterization of the fibers was made by the measurement of their diameters and lengths on samples of randomly selected 100 fibers from three different batches. The distribution of fibre length and diameter is displayed in Figure 2.
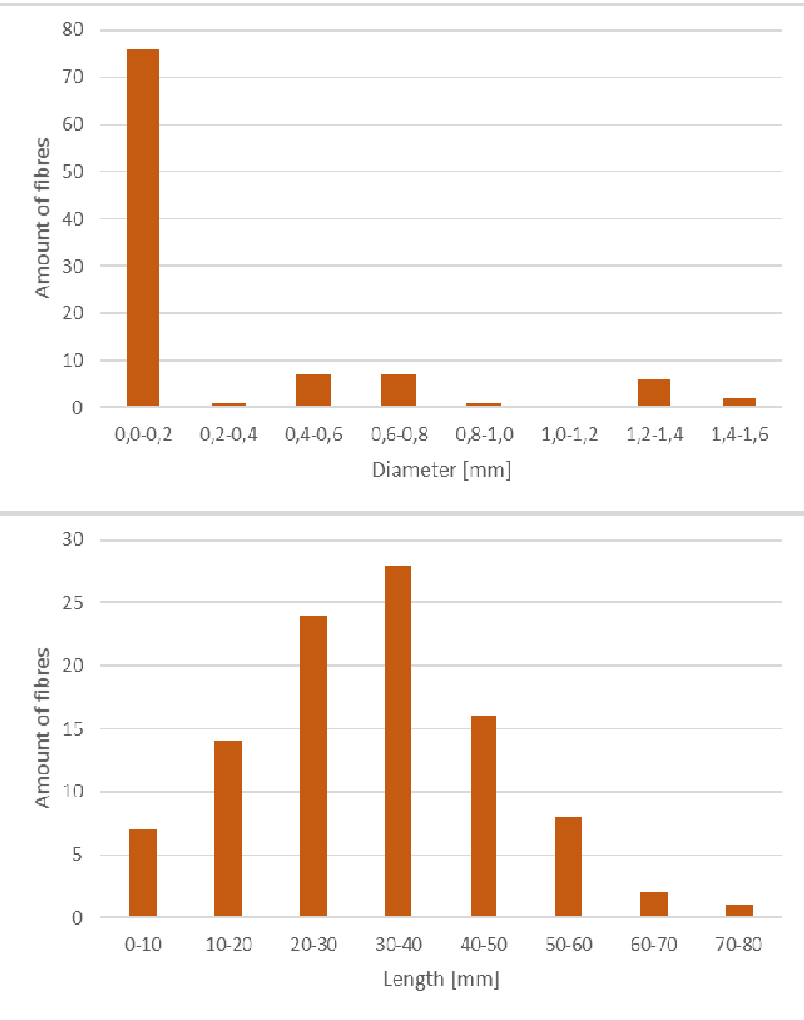

Fig. 2. Distribution of fibre diameter and length

Specimens with three different volume fractions of fibre reinforcement were prepared using waste fibre. The components and mix proportion (in kg. $\mathrm{m}^{-3}$ ) of the slurry are given in Table 1 .

Table 1. Components and mix proportions

\begin{tabular}{|l|l|l|}
\hline Designation/component & SIFCON & UHPFRC \\
\hline Cement CEM 52.5R Mokra, CR & 990 & 955 \\
\hline Fine aggregate 0-1 mm, Bzenec, CR & 890 & 143 \\
\hline Silica fume Elkem 940U & 78 & 1100 \\
\hline Superplasticizer Glenium ACE 446 & 12 & 16 \\
\hline Water & 300 & 230 \\
\hline
\end{tabular}


SIFCON with industrial steel fibres (10\% by vol.) and high-performance fibre concrete with $4 \%$ by vol. of the fibres were also cast and tested for comparison purposes. The fibres DE 30/06N (KrampeHarex, hooked ends, length $30 \mathrm{~mm}$, diameter $0.6 \mathrm{~mm}$ ) were used as the reinforcement for the reference specimens, as previous studies revealed their best performance in term of production technology. The manufacturing process of SIFCON involved preplacing of the steel fibres into the mould with subsequent pouring of the slurry over the pre-placed fibres. The mixing procedure of the reference specimen UHPFRC was as follows: cement, sand and microsilica were dry-mixed, then required quantity of water with plasticizer was added. At the end of mixing, steel fibres were added. The test specimens were demoulded after 24 hours and were cured for 28 days in curing water ponds.

For technological feasibility test, the specimens (100x100x400 mm) with $5-12.5 \%$ by vol. $(2.5 \%$ step) were prepared. After demoulding, the ultrasonic test was adopted to assess the homogeneity of the specimens, using the Proceq Tico device with $54 \mathrm{kHz}$ probe. The velocity of ultrasonic wave was measured at 10 determined spots. The velocity of sound wave in the material can be expressed as: $\mathrm{V}=\mathrm{L} / \mathrm{t}$. [13], where " $\mathrm{L}$ " is a travel distance and " $\mathrm{t}$ " a propagation time. The measurement of ultrasonic pulse velocity can be used to check the concrete homogeneity and to control the quality of concrete products by evaluation of the velocity variation. The velocity variation coefficient can be calculated according to the following formula: $\Delta=\left(\left(\mathrm{v}_{\max }-\mathrm{v}_{\min }\right)^{*} 100\right) / \mathrm{v}_{\min }$, where $\mathrm{v}_{\max } / \mathrm{v}_{\min }$ are maximal/minimal values of ultrasonic velocity obtained. For high performance concrete, according to the methodology based on ČSN 731371 standard, $\Delta$ must not exceed $7.5 \%$ for the tested specimen to be evaluated as homogenous.

For the bulk density, compressive and flexural strength investigation the prism specimens of dimensions 400x100x100 mm were cast. The mechanical parameters were obtained using universal strength testing machine TIRAtest 2710, R58/02. The compressive and flexural load was applied in quasistatic conditions at speed of $3 \mathrm{~mm} / \mathrm{min}$.

The blast tests were performed using modified methodology M-T0-VTU0 10/09. The methodology was upgraded to cover two tests. First test can be described as follows: The test specimen (500x500x40 $\mathrm{mm}$ ) is fixed in the frame of the steel stand, which is placed on the solid foundation. The sphere-shaped plastic high explosive Semtex 10, weighting $150 \mathrm{~g}$, is used as testing charge. The weight and distance (100 $\mathrm{mm}$ from the test specimen) of the testing charge was adjusted to be strong enough to cause the significant visible damage of the specimens, including fragmentation. Under the stand, the check panel consisting of hardboard-polystyrene-aluminium plate sandwich is placed. Observed and evaluated parameters are the weight of created secondary fragments and their destructive power expressed as the degree of damage of the check panel. Second test covers the loading of the specimen fixed in the stand with the charge $100 \mathrm{~g}$ of Semtex 10. The weight for this test was adjusted to cause the low-level damage (small cracks, the slab should remain integral). The change of the ultrasonic

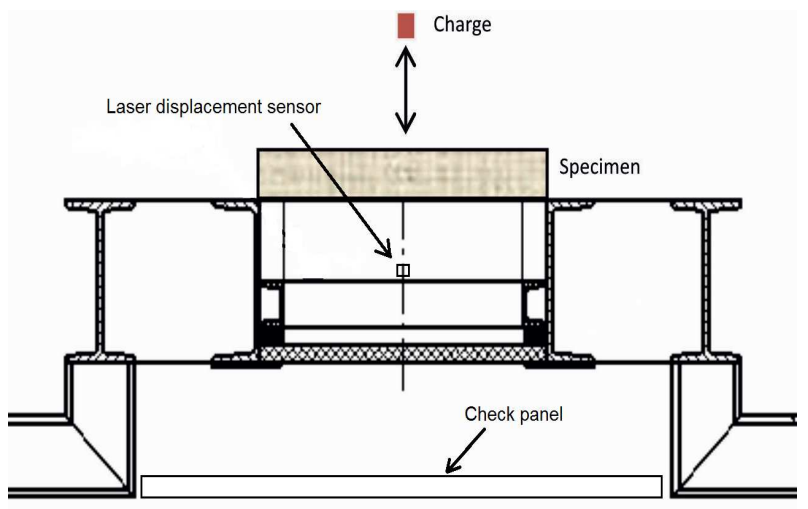

Fig. 3. Schematic view of test rig, arrangement during blast test

wave transit time at four measuring points before and after test was evaluated. The rate of the change of this parameter is directly connected to the damage of material. The scheme of the test rig is depicted in Figure 3. The distance of the charge was same as in the previous test $-100 \mathrm{~mm}$. Additionally, the static and dynamic deflection of the centre of the test slab is measured by the laser sensor optoNCDT ILD2300. The lower the static deflection, the better the performance of the material under the blast load can be expected. The data obtained from both tests corresponds well and give enough information to create good overview about how the particular material performs under blast load; and materials can be compared easily.

\subsection{Results and discussion}

\subsubsection{Technological feasibility}

Moulds were filled with $5-12.5 \%$ by vol. of fibres. 5 and $12.5 \%$ of the fibers were evaluated as the threshold values for efficient filling of the moulds under 5\%, the mould was not fully filled, over $12.5 \%$, the structure was so dense, that no more fibres were possible to be placed in the mould even the vibration was adopted. The results of ultrasonic velocity measurements represented by calculated velocity variation coefficient are summarized in Table 2. The specimen with $5.0 \%$ of fibres did not achieve satisfactory homogeneity $(\Delta=8.4 \%)$, due to insufficient fibre amount for creation the uniform skeleton, which corresponds with the findings published in study [10]. All the other specimens showed very good homogeneity-regardless of the measuring point, the ultrasonic velocities of these specimens remain almost constant, with $\Delta$ lower than $5 \%$. 
Table 2. Calculated velocity variation coefficient

\begin{tabular}{|l|c|}
\hline Designation & $\begin{array}{c}\text { Velocity variation coefficient } \\
{[\%]}\end{array}$ \\
\hline SIF $5.0 \%$ & 8.4 \\
\hline SIF 7.5\% & 4.8 \\
\hline SIF $10.0 \%$ & 4.4 \\
\hline SIF $12.5 \%$ & 3.1 \\
\hline
\end{tabular}

\subsubsection{Quasi-static mechanical tests}

Results of the quasi-static mechanical tests are presented in Table 3, the average value of five specimens is presented. As seen in the Table 3, raising of the fibre volume fraction causes increase of the compressive and most noticeable flexural strength - similarly to the SIFCONs with industrial fibres [14].

Table 3. Quasi-static mechanical tests and bulk density

\begin{tabular}{|l|c|c|c|}
\hline Designation & $\begin{array}{c}\text { Bulk } \\
\text { density } \\
{\left[\text { kg.m }^{-3}\right]}\end{array}$ & $\begin{array}{c}\text { Compressive } \\
\text { strength } \\
{[\mathbf{M P a}]}\end{array}$ & $\begin{array}{c}\text { Flexural } \\
\text { strength } \\
{[\mathbf{M P a}]}\end{array}$ \\
\hline SIF 5.0\% & 2,488 & 112.0 & 18.3 \\
\hline SIF 7.5\% & 2,510 & 115.0 & 20.8 \\
\hline SIF 10.0\% & 2,550 & 121.7 & 23.9 \\
\hline UHPFRC 4\% & 2,510 & 146.1 & 26.2 \\
\hline $\begin{array}{l}\text { SIF 10.0\% } \\
\text { REF }\end{array}$ & 2,585 & 120.9 & 25.7 \\
\hline
\end{tabular}

The strength values obtained in the case of specimen SIF $10.0 \%$ are very closed to the SIF $10.0 \%$ REF with industrial fibres.

\subsubsection{Blast tests}

The main results of both parts of the blast tests are summarized in Table 4. The test configuration is depicted in Fig. 4, the example of the output of the dynamic deflection measurement shows the graph in Fig. 5. The results of both tests correspond well. Thus, the measurement of the change of the ultrasonic wave transit time can be confirmed as simple, quick and effective method how to assess the blast resistance of the specimens more accurately than just by visual assessment of the damage level of the specimen and check desks. In addition, for this test, less amount of the explosive charge is needed, which reduces the requirements on the testing site and thus costs connected with the testing.

Table 4. Results of the blast tests

\begin{tabular}{|c|c|c|c|}
\hline Designation & $\begin{array}{c}\text { Dynamic } \\
\text { /static } \\
\text { deflection } \\
{[\mathrm{mm}]}\end{array}$ & $\begin{array}{c}\text { Increase } \\
\text { of US } \\
\text { wave } \\
\text { transit } \\
\text { time [\%] }\end{array}$ & $\begin{array}{l}\text { Fragment } \\
\text { weight }[\mathrm{g}]\end{array}$ \\
\hline \multirow{4}{*}{ SIF $5.0 \%$} & \multirow{4}{*}{$14.17 / 3.49$} & 112.0 & \multirow{4}{*}{298.3} \\
\hline & & 238.2 & \\
\hline & & 380.1 & \\
\hline & & 311.3 & \\
\hline
\end{tabular}

\begin{tabular}{|c|c|c|c|}
\hline \multirow{4}{*}{ SIF $7.5 \%$} & \multirow{4}{*}{$10.99 / 3.51$} & 76.4 & \multirow{4}{*}{42.0} \\
\hline & & 113.7 & \\
\hline & & 114.4 & \\
\hline & & 117.3 & \\
\hline \multirow{4}{*}{ SIF $10.0 \%$} & \multirow{4}{*}{$11.02 / 2.87$} & 52.2 & \multirow{4}{*}{23.9} \\
\hline & & 119.4 & \\
\hline & & 121.1 & \\
\hline & & 112.3 & \\
\hline \multirow{4}{*}{ UHPFRC $4 \%$} & \multirow{4}{*}{$10.8 / 2.4$} & 55.92 & \multirow{4}{*}{232.0} \\
\hline & & 173.58 & \\
\hline & & 150.1 & \\
\hline & & 144.1 & \\
\hline \multirow{3}{*}{$\begin{array}{l}\text { SIF } 10.0 \% \\
\text { REF }\end{array}$} & \multirow{3}{*}{$12.5 / 2.3$} & 120.9 & \multirow{3}{*}{84.0} \\
\hline & & 181.1 & \\
\hline & & $\begin{array}{c}100.6 \\
98.7\end{array}$ & \\
\hline
\end{tabular}

The blast resistance of the specimens with waste steel fibres rises with increasing amount of incorporated fibres. The specimen with $5 \%$ of fibres showed high rate of fragmentation (see Fig. 6 and Table 4). Observed fragments were in form of small aggregates up to $5 \mathrm{~mm}$ size. The check panels showed numerous indentations, but without perforation. The increase of the ultrasonic wave transit time was in range 112.0 to $380.0 \%$, which implies the high rate of internal damage. The dynamic deflection was the highest of all tested specimens $(14.17 \mathrm{~mm})$. Specimen with $7.5 \%$ of waste fibres showed significantly lower fragmentation, dynamic deflection and ultrasonic wave transit time change, compared to the SIF 5\% specimen. Ejected fragments' size was up to $3 \mathrm{~mm}$, indentation but no perforation was observed on the check panel. The best results were obtained in the case of SIF $10.0 \%$ specimen. The slab's integrity didn't suffer, only some cracks were observed and a few flat splinters were split off from the surface layer $(23.9 \mathrm{~g})$, without perforating the check panel. Test

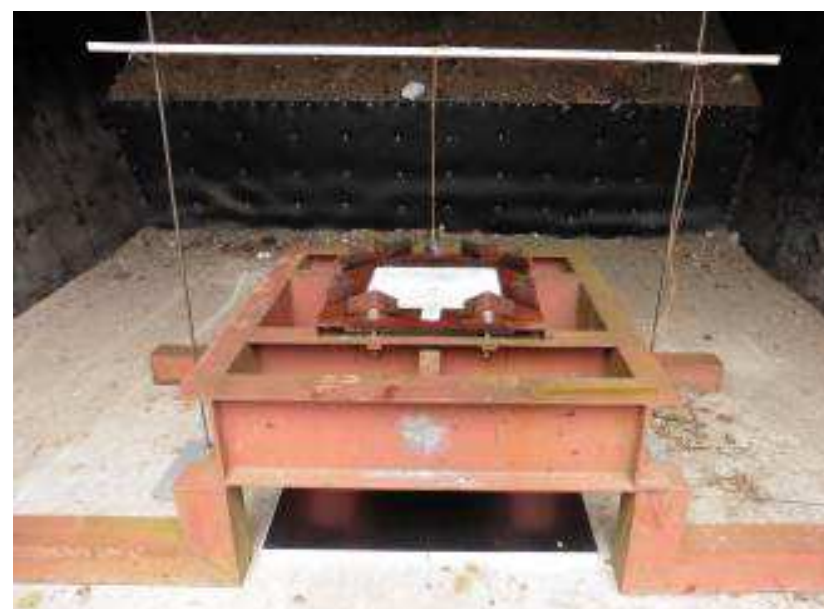

slab prepared from UHPFRC with $4 \%$ of commercial steel fibres showed different mode of fragmentation only one fragment $(232.0 \mathrm{~g})$ was ejected, creating conic indentation ( $2 \mathrm{~mm}$ depth) without perforation. Internal damage represented

Fig. 4. Test configuration 
by change of the ultrasonic wave transit time was higher compared to slab SIF 7.5\% and SIF10.0\%. Specimen SIF $10.0 \%$ REF with commercial steel fibres showed worse performance compared to the specimen with $10.0 \%$ of waste fibres, the weight of the debris was $84.0 \mathrm{~g}$ (compared to $23.9 \mathrm{~g}$ ) and the increase of ultrasonic wave transit time was higher as

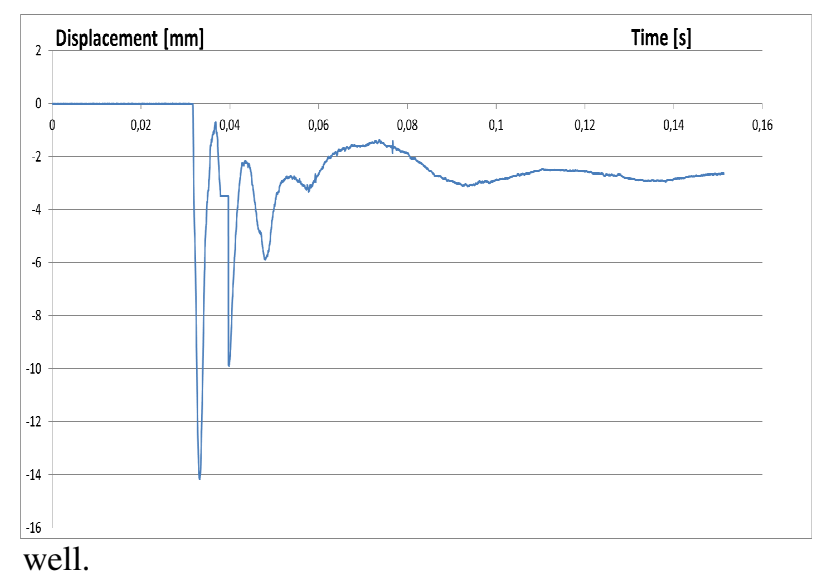

Fig. 5. Example of the output of the dynamic deflection measurement

Comparing the SIFCON specimens, better performance of specimens with waste steel fibres under the blast load was observed, which is probably caused by their hybrid character. Waste fibres from tires are characterized by different shape parameters with high rate of thin shorter fibres (see the distribution in Fig. 2). At quasistatic load, the fracture processes of concrete loaded in tension begin by the formation of numerous fine microcracks; if the tensile load continues to increase, these microcracks connect with each other and form larger cracks, which subsequently leads to failure. Short fibres can bridge microcracks, which increases tensile strength, long fibres bridge macrocracks, so they can provide a stable post-peak response. For the blast load, as it is extremely fast phenomenon, this classical approach cannot be fully adopted, but the hybrid fibre reinforcement is still beneficial, because the same volume content of waste fibres contains more fibres than the commercial ones, so the fibres can be more homogeneously distributed within the concrete, with fewer unreinforced spaces. [15, 16] In this model, thicker and longer fibres help to keep the overall integrity of the material, whereas the shorter and thinner fibres protect the slab from the fragmentation. All the SIFCON specimens (except for SIF 5.0\%) outperformed ultra-high-performance concrete, which is caused primarily by the higher fiber amount contained in SIFCON specimens.

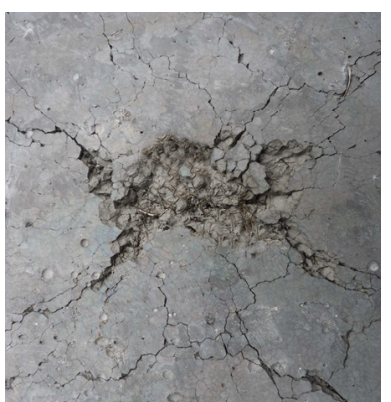

SIF $5.0 \%$

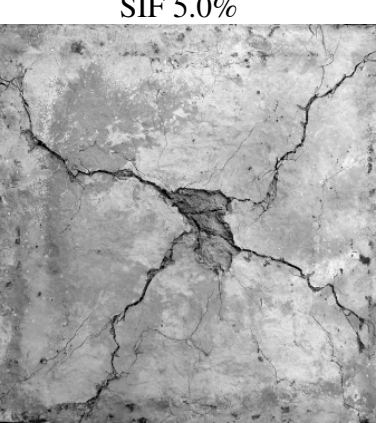

HPFRC $4 \%$
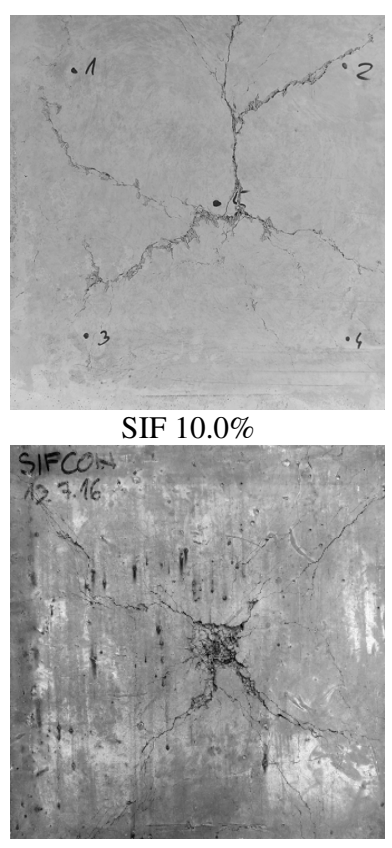

SIF $10.0 \%$ REF
Fig. 6. Specimens after the blast test $-150 \mathrm{~g}$ Semtex 10

\section{Conclusions}

This paper summarizes the results of research on slurry infiltrated fibre concrete reinforced with waste steel fibres from tires. Technological feasibility was assessed and mechanical parameters both at quasistatic and blast load were determined. Obtained results were compared to SIFCON with industrial fibres and HPFRC. The modified methodology for blast resistance assessment is also presented. Following conclusions can be drawn:

- Waste steel fibres have significant variations in their geometrical properties, the length varies between 0.5-80 mm, diameter between 0.03-1.6 mm. Dimension diversity and the bulk nature of the waste fibres were proved not to be obstacle in slurry infiltration technology. Bulk character of the fibres helps to create stable skeleton and fibre mix act like natural hybrid reinforcement. Excellent infiltration level and homogeneity of the specimens can be achieved. Using of unclassified waste steel fibres from tires in SIFCON is feasible from technological point of view.

-The optimal fibre amount for SIFCON technology was determined between 7.5 and $10.0 \%$ by vol. The higher the amount of fibres, the better homogeneity is achieved -Mechanical properties (flexural strength, compressive strength and total absorbed energy) increases with raising waste fibre volume fraction.

-Replacement of industrial fibres by waste fibres does not significantly reduce mechanical properties of the SIFCON at quasi-static load.

-Regarding the blast load, SIFCON with waste steel fibres outperformed the SIFCON with industrial fibres, which is attributed to the hybrid nature of the 
fibres. Thicker and longer fibres help to keep the overall integrity of the material, whereas the shorter and thinner fibres protect the slab from fragmentation. Using of short low diameter fibres means less unreinforced "matrix-only" areas.

-Using of waste fibres in SIFCON technology can reduce the price of this composite by $70 \%$ by keeping the SIFCON extraordinary properties, which makes it very competitive material in the area of precast concrete.

\section{Acknowledgement}

The authors wish to express their gratitude and sincere appreciation to the authority of The Technology Agency of the Czech Republic, project No. TE02000162 - Centre of advanced materials and technologies for protection and safety enhancement, for financial support.

\section{References}

1. O. Sengul, Constr. Build. Mater. 122 (2016)

2. A. Evans and E. Evans, The waste and resources action Programme report (2006)

3. Markets for wire and fiber from waste tires, Contractor's report, California Department of resources recycling and recovery (2013)

4. G. Centonze, M. Leone and M.A. Aiello, Constr. Build. Mater. 36 (2012)

5. Ch. G. Papakonstantinou and M.J. Tobolski, Cement Concrete Res. 36 (2006)

6. M.A. Aiello, F. Leuzi, G. Centonze and A. Maffezzoli, Waste manag. 29 (2009)

7. A. Caggiano, H. Xargay, P. Folino and E. Martinelli, Cement Concr. Compos. 62 (2015)

8. Y.Wang, H.C. Wu and V.C. Li, Mater. Civ. Eng. 12 (2000)

9. A.G. Graeff, K. Pilakoutas, K. Neocleous, M. Vania and N.N. Peres, Eng. Struct., 45 (2012)

10. D.R. Lankard, Concrete Int., 6

11. H. Sudarsana Rao and N.V. Ramana, Indian J. Eng. Mater. Sci., 12 (2005)

12. H. Sudarsana Rao, N.V. Ramana and K. Gnaneswar, Indian J. Eng. Mater. Sci. 15 (2008)

13. M. Benachia, O. Jalbaud, X. Roquier, A. H. Alaoui and Y. Burtschell, Alexandria Engineering Journal 54 (2015)

14. Drdlová, R. Řídký and R. Čechmánek, Mater. Sci. Forum 865 (2016)

15. M. Drdlová, J. Buchar, J. Krátký, R. Řídký, Struct. Concrete 16, 4 (2015)

16. R. Čechmánek, M. Drdlová, M. Boháč, Solid State Phenomena 259 (2017) 